\title{
Precision Medicine for Ischemic Stroke, Let Us Move Beyond Time Is Brain
}

\author{
Shao-Hua Yang ${ }^{1}$ (D) $\cdot$ Min Lou $^{2} \cdot$ Benyan Luo $^{3} \cdot$ Wei-Jian Jiang ${ }^{4} \cdot$ Ran Liu $^{1}$
}

Received: 11 August 2017 / Accepted: 16 August 2017 /Published online: 29 August 2017

(C) Springer Science+Business Media, LLC 2017

Until 1995, treatment of ischemic stroke consisted exclusively of efforts to prevent recurrence. Since that time, the introduction of recombinant tissue plasminogen activator (rtPA) treatment has significantly improved morbidity and mortality of ischemic stroke [1]. Ischemic stroke is treatable but time is critical. The term "time is brain" has been coined for acute stroke intervention, even before the rtPA trials, to emphasize that the human brain is rapidly and irreversibly lost as stroke progresses and that therapeutic interventions should be emergently pursued [2-5]. Two decades after the approval of intravenous rtPA for the treatment of ischemic stroke, interventions to reopen an occluded artery through thrombolysis and mechanical thrombectomy remain the only and first priority in ischemic stroke treatment. Accordingly, dramatic effort has been investing to reduce the time from stroke onset to treatment and arrival-to-puncture time for ischemic stroke patients. It is anticipated that an interdisciplinary and rapid response to the emergence of stroke intervention can result in dramatic impact of thrombolysis on this public health problem. Unfortunately,

Shao-Hua Yang

shaohua.yang@unthsc.edu

1 Center for Neuroscience Discovery, Institute for Healthy Aging, University of North Texas Health Science Center, 3500 Camp Bowie Blvd., Fort Worth, TX 76107, USA

2 Department of Neurology, the Second Affiliated Hospital, School of Medicine, Zhejiang University, 88 Jiefang Rd,

Hangzhou, Zhejiang 310009, China

3 Department of Neurology, the First Affiliated Hospital, School of Medicine, Zhejiang University, 79 Qingchun Rd, Hangzhou, Zhejiang 310003, China

4 Department of Vascular Neurosurgery, New Era Stroke Care and Research Institute, the PLA Rocket Force General Hospital, Beijing 100088, China the number of ischemic stroke patients who are treated with thrombolytic therapy is still disappointingly low.

Time is not absolute but relative in term of stroke treatment. Therapeutic time window for ischemic stroke has been continually evolving in the last two decades. The original recommended therapeutic window of intravenous rtPA for ischemic stroke was $3 \mathrm{~h}$ of stroke onset [1]. At present, intravenous thrombolysis is for patients with acute onset stroke within $4.5 \mathrm{~h}$, provided that hemorrhage or other contraindications are excluded $[6,7]$. Mechanic thrombectomy, in addition to intravenous thrombolysis within $4.5 \mathrm{~h}$, when eligible, is recommended to treat acute stroke patients with larger artery occlusion in the anterior circulation up to $6 \mathrm{~h}$ after symptom onset [7]. There is increasing experimental and clinical evidence supporting a variable therapeutic window that may exceed 6 to $8 \mathrm{~h}$. Case study has demonstrated that symptoms can be resolved through endovascular recanalization at the chronic stage up to 80 days after stroke symptom onset [8]. On the other hand, reperfusion after ischemic stroke within the therapeutic window does not necessary lead to improvement of clinical outcome. There is often a mismatch in the clinical trials with higher reperfusion rates but lesser rates of functional recovery, potentially due to futile recanalization. The futile recanalization occurs when successful recanalization fails to improve the functional outcome and accounts for 30-50\% revascularization cases in various endovascular trials $[9,10]$. Taken together, therapeutic window is not equal to the time window. There are many factors that may impact the therapeutic window of reperfusion therapy for ischemic stroke. For example, time to treatment has been found to be a predictor of outcome only when collaterals were excluded from the model, indicating the important role of collaterals for the time window of ischemic stroke intervention [11]. Furthermore, it has been found that the association between endovascular reperfusion and improved functional and radiologic outcomes is 
not time dependent in patients with a perfusion-diffusion mismatch [12].

The permanent brain damage is related to both the duration and severity of ischemia. Without measurement of ischemic severity, time is the only and primary factor defining the therapeutic window for ischemic stroke intervention [13]. Precision medicine was initiated with a primary focus on cancer and is rapidly expanding to the whole range of health and disease, including stroke [14]. The highly heterogeneous stroke population and imprecise therapeutic time window lead to a large number of patients in the current stroke trials while a minority of participants drove the cohort effect. The precision medicine calls for novel strategies to define a therapeutic window that take individual variability into account for ischemic stroke treatment beyond the time. Advances in neuroimaging technologies provide diagnostic tools to evaluate the physiological status of intracranial vessels, cerebral hemodynamics, and possible degree of reversibility of ischemic brain damage $[15,16]$. "Physiology is brain" has been created to advocate the use of physiological neuroimaging to guide stroke therapy [17]. Physiological neuroimaging has been extensively evaluated in therapeutic time windows where the margin of benefit of reperfusion therapy is much smaller. The perfusiondiffusion mismatch has been believed to be a practical and approximate measure of the tissue at risk, thus, a physiological guidance for thrombolytic intervention. However, recent studies have convicted that mismatch does not optimally define the ischemic penumbra [18]. Hitherto, the intensive research and extensive use of the current neuroimaging modalities have led to mixed results and there is lack of evidence supporting the use of physiological neuroimaging to expanding the therapeutic time window for reperfusion therapy [16, 19-22]. Novel precision neuroimaging technology remains to be developed to define the precise therapeutic window for the treatment of individual stroke patient [23].

The human brain is by far the most expensive organ in term of energy expenditure in the whole body. The human brain constitutes only $2 \%$ of the body weight, but receives $15 \%$ of cardiac output, accounts for almost $20 \%$ of the total oxygen consumption, and consumes approximately $25 \%$ of total body glucose utilization. In addition, the brain has very limited energy storage and relays on coincidental regulation of cerebral blood flow to match the local brain activity and renders it highly vulnerable to ischemic attack. Ischemic stroke is a cerebrovascular event, initiated by occlusion of a cerebral artery and result in cellular energy metabolism crisis and ultimate brain damage. While the pathophysiology during ischemic stroke is highly complex, reduction or absent metabolic activity of brain cells represents the initiative and end point of ischemic stroke. Metabolism dictates the brain function and the degree of reversibility brain tissue after ischemic stroke. Ultimately, metabolism is brain. The current clinical neuroimaging technology does not provide direct measurement for brain metabolism. Precision neuroimaging on brain metabolism may provide more effective tool in the selection of stroke patients for reperfusion intervention [24]. Emerging neuroimaging research on proton MR spectroscopy (MRS), sodium imaging, and oxygen imaging may provide metabolic imaging technique to precisely identify salvageable ischemic lesion in individual patient independent of time $[25,26]$. There is no doubt that time is still brain in term of acute stroke intervention. Metabolic neuroimaging with the current imaging modalities and novel technologies may realize the promise of precision medicine to provide precision stroke diagnostic tool for personalized intervention.

Funding This work was partly supported by the National Institutes of Health grants 1R21NS087209-01A1 (SY) and R01NS088596 (SY), and American Heart Association SDG16960084 (RL).

\section{Compliance with Ethical Standards}

Conflict of Interest The authors declare that they have no conflict of interest.

Ethical Approval This article does not contain any studies with human participants or animals performed by any of the authors.

\section{References}

1. The National Institute of Neurological Disorders and Stroke rt-PA Stroke Study Group. Tissue plasminogen activator for acute ischemic stroke. N Engl J Med. 1995;333:1581-7.

2. Gomez CR. Editorial: time is brain! J Stroke Cerebrovasc Dis. 1993;3:1-2.

3. Hill MD, Hachinski V. Stroke treatment: time is brain. Lancet. 1998;352(Suppl 3):SIII10-4.

4. Adams HP Jr. Treating ischemic stroke as an emergency. Arch Neurol. 1998;55:457-61.

5. Saver JL. Time is brain - quantified. Stroke. 2006;37:263-6.

6. Del Zoppo GJ, Saver JL, Jauch EC, Adams HP Jr. Expansion of the time window for treatment of acute ischemic stroke with intravenous tissue plasminogen activator: a science advisory from the American Heart Association/American Stroke Association. Stroke. 2009;40:2945-8.

7. Mikulik R, Wahlgren N. Treatment of acute stroke: an update. J Intern Med. 2015;278:145-65.

8. Yu W, Kostanian V, Fisher M. Endovascular recanalization of basilar artery occlusion 80 days after symptom onset. Stroke. 2007;38: 1387-9.

9. Molina CA. Futile recanalization in mechanical embolectomy trials: a call to improve selection of patients for revascularization. Stroke. 2010;41:842-3.

10. Appireddy RM, Demchuk AM, Goyal M, Menon BK, Eesa M, Choi $\mathrm{P}$, et al. Endovascular therapy for ischemic stroke. J Clin Neurol. 2015;11:1-8.

11. Galimanis A, Jung S, Mono ML, Fischer U, Findling O, Weck A, et al. Endovascular therapy of 623 patients with anterior circulation stroke. Stroke. 2012;43:1052-7.

12. Lansberg MG, Cereda CW, Mlynash M, Mishra NK, Inoue M, Kemp $\mathrm{S}$, et al. Response to endovascular reperfusion is not time-dependent in patients with salvageable tissue. Neurology. 2015;85:708-14. 
13. Sacco RL, Kasner SE, Broderick JP, Caplan LR, Connors JJ, Culebras A, et al. An updated definition of stroke for the 21st century: a statement for healthcare professionals from the American Heart Association/American Stroke Association. Stroke. 2013;44:2064-89.

14. Collins FS, Varmus H. A new initiative on precision medicine. $\mathrm{N}$ Engl J Med. 2015;372:793-5.

15. Adams HP Jr, Adams RJ, Brott T, del Zoppo GJ, Furlan A, Goldstein LB, et al. Guidelines for the early management of patients with ischemic stroke: a scientific statement from the Stroke Council of the American Stroke Association. Stroke. 2003;34: 1056-83.

16. Bivard A, Levi C, Krishnamurthy V, McElduff P, Miteff F, Spratt $\mathrm{NJ}$, et al. Perfusion computed tomography to assist decision making for stroke thrombolysis. Brain. 2015;138:1919-31.

17. Gonzalez RG. Imaging-guided acute ischemic stroke therapy: from "time is brain" to "physiology is brain". AJNR Am J Neuroradiol. 2006;27:728-35.

18. Chen F, Ni YC. Magnetic resonance diffusion-perfusion mismatch in acute ischemic stroke: an update. World J Radiol. 2012;4:63-74.

19. Davis SM, Donnan GA, Parsons MW, Levi C, Butcher KS, Peeters $\mathrm{A}$, et al. Effects of alteplase beyond $3 \mathrm{~h}$ after stroke in the Echoplanar
Imaging Thrombolytic Evaluation Trial (EPITHET): a placebocontrolled randomised trial. Lancet Neurol. 2008;7:299-309.

20. Lansberg MG, Straka M, Kemp S, Mlynash M, Wechsler LR, Jovin $\mathrm{TG}$, et al. MRI profile and response to endovascular reperfusion after stroke (DEFUSE 2): a prospective cohort study. Lancet Neurol. 2012;11:860-7.

21. Alawneh J, Baron J-C. Penumbral imaging in acute stroke: a triumph of hope over experience? ACNR. 2014;14:18-23.

22. Agarwal S, Warburton EA, Baron JC. From time is brain to physiology is brain: a case for reflection in acute stroke treatment decisions. Brain. 2015;138:1768-70.

23. Feldmann E, Liebeskind DS. Developing precision stroke imaging. Front Neurol. 2014;5:29.

24. Dani KA, Warach S. Metabolic imaging of ischemic stroke: the present and future. AJNR Am J Neuroradiol. 2014;35:S37-43.

25. Mandal PK. Brain metabolic mapping with MRS: a potent noninvasive tool for clinical diagnosis of brain disorders. AJNR Am J Neuroradiol. 2014;35:S1-3.

26. Christen T, Bolar DS, Zaharchuk G. Imaging brain oxygenation with MRI using blood oxygenation approaches: methods, validation, and clinical applications. AJNR Am J Neuroradiol. 2013;34: 1113-23. 